\title{
Carranza y los Estados Unidos. Unas relaciones difíciles vistas desde España ${ }^{1}$
}

\author{
Rosario Sevilla Soler
}

Escuela de Estudios Hispano-Americanos. CSIC. Sevilla

Este trabajo pretende ofrecer una visión singular de las relaciones entre uno de los líderes más significativos de la Revolución Mexicana y los Estados Unidos. No es un análisis histórico de esas relaciones, sino un relato de cómo se percibió la intromisión de los norteamericanos en los asuntos mexicanos desde una región de España, Andalucía, que tan ligada estuvo en otro tiempo a América. Se trata, en definitiva, de intentar un acercamiento a la imagen que la sociedad española, y más concretamente la sevillana, tuvo de aquellas relaciones, a través del único medio de que disponía: la prensa de su ciudad, la que le llegaba por suscripción desde Madrid, y los escritos de algunos intelectuales de la época preocupados por la cuestión.

PALABRAS CLAVE: Revolución Mexicana, relaciones internacionales, opinión pública.

The purpose of this study is to show a view of the relation between one of the most relevant leaders of the Mexican Revolution and the United States. It isn't a historical analysis but a report on how American interferences in Mexican affairs was seen from a Spanish region (Andalucía), historically linked with America. Actually, it is an approach to the image that Spanish society, and mostly the Sevillian one, had of those relations. And we'll try to do it, through the only media available: local newspapers (and those which came from Madrid as a result of subscriptions), and the writings of some contemporary intellectuals concerned with the matter.

KEYwORDS: Mexican Revolution, international relationship, public opinion.

\section{El primer reconocimiento a Carranza}

Con el pretexto de los daños que sufrían sus ciudadanos por los enfrentamientos armados, la intervención de los Estados Unidos en el proceso revolucionario mexicano se inició en los primeros momentos del levantamiento maderista; pero no desaparecería al terminar la llamada etapa bélica de la Revolución, aunque, en algunos aspectos, tomara una forma 03215.

1 Este trabajo se ha realizado dentro de los proyectos HUM2006-05449 (PNI), y PO7-HUM- 
diferente. $\mathrm{Y}$ es que los problemas entre ambos países no terminarían con la llegada de Carranza al poder, a pesar de que lo hubiera logrado éste, al menos en parte, con la ayuda de Washington. ${ }^{2}$

De hecho, en virtud del "nacionalismo" del mandatario mexicano, que entraba en colisión con poderosos intereses norteamericanos, durante su mandato se llegó a algunos de los momentos más tensos en las relaciones bilaterales. Y como había ocurrido antes, especialmente a raíz de la muerte de Madero, las ingerencias estadounidenses en la política mexicana no podían ser bien vistas desde España, cuya prensa, con escasas excepciones, y en concordancia con los intelectuales de la época, tenía que denostar esta actitud del coloso del norte que tanto le recordaba a la guerra de Cuba.

En esta fase del proceso, los Estados Unidos utilizaron, esencialmente, dos bazas - aunque sin descartar otras como el empleo de tropas - para conseguir sus propósitos en México; por una parte, y como habían hecho antes en Cuba y harían después en otros lugares, la propaganda, intentando disfrazar su actuación ante la opinión pública internacional con supuestos motivos humanitarios. Por otra, la presión política que, con frecuencia, sobrepasó todos los límites en cuanto a las normas que deben regir las relaciones diplomáticas cuando no existe, como era el caso, un conflicto armado entre países. ${ }^{3}$

Como muestra de ello, cuando a comienzos de 1915 Álvaro Obregón ocupó la capital tras la marcha de Huerta, el Departamento de Estado le hizo llegar una nota, "insolentísima" a juicio de muchos observadores, en la que se le comunicaba que se le haría responsable, junto al primer jefe, de "cualquier desmán que cometiera el pueblo de México en contra de los extranjeros". ${ }^{4} \mathrm{Y}$ desde entonces la situación no haría sino empeorar ya que, en la medida en que algunos "jefes revolucionarios" seguían en rebeldía y la lucha proseguía, se mantenía la inquietud en Washington; apenas sus tropas habían salido de Veracruz tras una larga y complicada negociación, cuando Wilson, afirmando que la situación mexicana era tan grave como

2 Sobre el cambio de actitud de los norteamericanos respecto al enfrentamiento HuertaCarranza, ver Ulloa, Berta: La Revolución Intervenida. Relaciones diplomáticas entre México y los Estados Unidos. (1910-1914), El Colegio de México, México, 1971, págs. 90-95.

3 La opinión que merecía a la prensa española la intervención norteamericana en América latina ha sido estudiada detalladamente en Sevilla Soler, Rosario: La Guerra de Cuba y la Memoria Colectiva, CSIC, Sevilla, 1996, y La Revolución Mexicana y la opinión pública española. La prensa sevillana frente al proceso de insurrección, CSIC, Madrid, 2005.

4 Alessio Robles, Miguel: Historia política de la Revolución Mexicana, Editorial Botas, Xochimilco, 1946, págs. 185-186. 
antes de la caída de Huerta, "avisaba" a las autoridades mexicanas sobre la necesidad de acabar cuanto antes con todo tipo de enfrentamiento armado.

A partir de ese momento las advertencias irían subiendo de tono, hasta el punto de que poco después, en el mes de junio, los Estados Unidos amenazaban claramente al país vecino; la administración norteamericana llegó a fijar un plazo a Villa y Carranza para acabar con sus diferencias, si no querían que ella tomara medidas drásticas. Sin parecer ofendido por semejante intromisión, Villa se mostró dispuesto a aceptar las consignas de Washington y, al menos en teoría, a negociar con los constitucionalistas. Carranza, por el contrario, protestó enérgicamente por lo que resultaba ser, en el mejor de los casos, una intromisión en los asuntos internos mexicanos y, en el peor, y así lo entendió él, una especie de ultimátum que llevaba implícita la amenaza de una nueva intervención armada. ${ }^{5}$

La respuesta del líder constitucionalista a las "recomendaciones" de los Estados Unidos le creó en ese país enemigos poderosos que, probablemente, condicionaron, al menos en parte, la política de su administración respecto a México. Ciertos grupos de presión estadounidenses intentaron que su gobierno apoyara las aspiraciones de Villa frente a las de Carranza; ${ }^{6}$ y es posible que el presidente Woodrow Wilson se dejara influir por ellos a la hora de retrasar el reconocimiento al gobierno carrancista hasta que su líder fuera ratificado en unas elecciones; pero no se dejó llevar por el camino que querían marcarle en cuanto a Villa y, al terminar el plazo que él mismo había señalado para que ambos líderes entablaran conversaciones sin que éstas hubieran siquiera empezado, no sólo no tomó las "drásticas medidas" que había anunciado sino que, como veremos más adelante, llegó a reconocer a Carranza sin esperar a su elección en unos comicios.?

Sólo cuando en el mes de agosto tuvo lugar un enfrentamiento entre tropas de ambos países en la zona fronteriza, el presidente norteamericano amagó de nuevo; pero, en lugar de intervenir militarmente como le pedían los sectores citados, y aunque no desechara por completo tal posibilidad, optó por recurrir en primer lugar a la vía diplomática. En esa línea, propuso la celebración de una conferencia de países latinoamericanos, con la

5 Knight, Alan: La Revolución Mexicana. Del porfiriato al nuevo régimen constitucional, t. II, Editorial Grijalbo, México, 1996, pág. 917.

6 Sobre el enfrentamiento Villa-Carranza, ver Meyer, Lorenzo: La Revolución Mexicana. 1910-1940, Dopesa, Barcelona, 1973, págs. 50-60.

7 Duroselle, Jean Baptiste: Política exterior de los Estados Unidos. De Wilson a Roosevelt. 1913-1945, Fondo de Cultura Económica (FCE), México, 1965, pág. 79. 
idea de que éstos pudieran presionar a los caudillos mexicanos y conseguir que terminaran con los conflictos armados.

Su iniciativa se plasmó en una invitación a Argentina, Brasil, Chile, Guatemala, Bolivia y Uruguay a apoyar su proyecto de pacificación. Dicho proyecto, decían los medios de comunicación españoles, contemplaba la posibilidad de una intervención del ejército norteamericano en el caso de que las conversaciones entre los líderes mexicanos fracasaran; eso sí, para que no pareciera una invasión estadounidense, se pretendía que los citados países hicieran alguna aportación de tropas, aunque fuera simbólica, para transmitir la imagen de que se trataba de una operación conjunta. Sin embargo, los participantes en la conferencia, añadían los diarios, no quisieron adquirir semejante compromiso; sólo accedieron a enviar un mensaje a los "jefes mexicanos" — que no tuvo demasiado éxito por cierto-, en el que se les conminaba a reconocer al gobierno provisional encabezado por Carranza y a deponer las armas. ${ }^{8}$

Ante el fracaso de su estrategia, Wilson decidió actuar en solitario para imponer sus condiciones. La primera de ellas sería, afirmaban los rotativos, la de "hacer reconocer que la presidencia de la república corresponde, con arreglo a la Constitución, a un miembro del antiguo gabinete del general Madero"; ese presidente, seguían diciendo, debería ser "aprobado por todas las facciones políticas" y por "las naciones participantes en la reunión" ya mencionada; contando con el aval internacional, el citado gabinete debería proceder a conceder una "amnistía general", y a la convocatoria de unas elecciones presidenciales que pudieran desarrollarse con normalidad. Para conseguir su propósito no dudó en utilizar la amenaza, advirtiendo directamente a los constitucionalistas que estaba "dispuesto a intervenir en México"; y para hacer creíble esa amenaza llegó a concentrar tropas en la frontera. ${ }^{9}$ Pero si la amenaza de que hablaba la prensa existió, no se llegó a cumplir; entre otras cosas porque, para entonces, las fuerzas constitucionalistas habían logrado reducir el movimiento zapatista a Morelos, mientras Villa, tras varias derrotas frente a Obregón, perdía incluso Ciudad Juárez, en su feudo de Chihuahua, y se veía obligado a retirarse en las montañas.

Por otra parte, al tiempo que mejoraban las relaciones de los constitucionalistas con los países europeos, fundamentales también para su estrate-

8 El Liberal de Sevilla, jueves 5 de agosto de 1915

9 Ibídem, viernes 13 de agosto y lunes 11 de octubre de 1915 . 
gia, la marcha de la guerra en el viejo continente forzó a los Estados Unidos a intentar conseguir la adhesión o, al menos, la neutralidad de su vecino, y Wilson no sólo disminuyó su presión sobre el gabinete carrancista sino que, en contra de lo afirmado poco antes por las publicaciones peninsulares, se mostró dispuesto a reconocer a la administración mexicana; ellas mismas contaron que el secretario de Estado norteamericano, "Mister Lansing", había "declarado que los representantes de Estados Unidos, Argentina, Brasil, Chile, Bolivia, Uruguay y Guatemala", reunidos en Nueva York, habían acordado "reconocer el gobierno de Carranza como gobierno de facto de México". No obstante, decían los periódicos, ese reconocimiento sólo se haría efectivo si se concedía una amnistía a todos los condenados por delitos políticos y se respetaba la "vida y hacienda" de los extranjeros residentes en el país. ${ }^{10}$

Detrás de esas exigencias latía la preocupación del gabinete Wilson no sólo, como argumentaba, por la vida de sus ciudadanos, sino por los efectos que podían tener en sus intereses las medidas legislativas constitucionalistas, de las que ya había tenido indicios en noviembre de 1914; en esa fecha Venustiano Carranza promulgaba un decreto por el que se cancelaban las concesiones mineras otorgadas en la etapa huertista. Ese decreto no fue aceptado por los Estados Unidos, que protestarían, además, por las posteriores medidas impositivas de las nuevas autoridades.

Pero Carranza, consciente de que el mandatario estadounidense se enfrentaba en aquellos momentos a otros problemas en el ámbito internacional, no se dio por aludido; y aquél, efectivamente comprometido con los asuntos europeos, terminó por ceder. El 19 de octubre de 1915, antes de que fuera ratificado en unas elecciones como había pedido en un principio, Washington reconocía a Carranza como jefe del Estado mexicano; ${ }^{11}$ y con los Estados Unidos lo hicieron también los gobiernos latinoamericanos y, poco después, la mayor parte de los europeos, incluidos los de España y Gran Bretaña. ${ }^{12}$

10 Ibídem, lunes 11 de octubre de 1915 .

11 Richmond, Douglas. W.: La lucha nacionalista de Venustiano Carranza 1893-1920, FCE, México, 1986, pág, 270. Ver también Duroselle: Política exterior..., pág. 81.

12 En este aspecto, la presión de los Estados Unidos y el desarrollo de la Guerra europea fueron decisivos para que gobiernos como el británico, enemigo declarado de los constitucionalistas, lo reconocieran. Ver sobre ello Meyer, L.: Su majestad británica contra la Revolución Mexicana. 1900 1950, El Colegio de México, México, 1951. Sobre las variables relaciones con España, ver Sevilla Soler, R: La Revolución Mexicana..., y Meyer, L.: El cactus y el olivo. Las relaciones de México y España en el siglo XX, Océano, México, 1991. 
No por ello, sin embargo, terminarían los problemas entre los dos países. Aunque la campaña del Bajío dejaba a Carranza como la única alternativa de poder viable, sus tropas no habían llegado a controlar por completo el territorio de la república. Villa había sido derrotado; pero con su paso a la guerrilla dificultaba la normalidad. Además, al contrario de lo que había ocurrido hasta entonces, entre los objetivos de sus ataques se encontraban también intereses norteamericanos; y es que el reconocimiento de éstos al gobierno carrancista había implicado, como es lógico, el embargo de armas con destino a los villistas, entre los que se creó un fuerte sentimiento "antiyanqui". Los asaltos a ciudadanos y empresas estadounidenses se convirtieron en algo normal, y los rumores sobre esas agresiones, supuestas o reales, se multiplicaron.

Como resultado de ello, los que, como el antiguo presidente Teodoro Roosevelt o el periodista William Randolph Hearst, reclamaban una acción armada en México en apoyo de los intereses petroleros fueron ganando adeptos en el Senado..$^{13} \mathrm{La}$ fuerza de esos grupos que presionaban a Wilson para que interviniera militarmente en México era considerable; y quedaría patente en enero de 1916, con motivo del asesinato de 16 ingenieros norteamericanos en Chihuahua a manos de las bandas villistas. ${ }^{14}$

Que tal suceso tuviera gran impacto en la opinión pública estadounidense puede considerarse normal; pero la dimensión que se dio a aquel hecho, alentada por los rotativos de aquel país - especialmente por los pertenecientes al periodista citado-, desborda todos los límites de lo razonable. El "alboroto" ocasionado en los Estados Unidos con ese pretexto fue tal, que, según decía la prensa española, llevó a la presentación en el Senado de "una proposición, solicitando la intervención armada de los Estados Unidos en el país vecino"; su fin sería, añadían, "terminar de una vez con las revueltas y las luchas internas que asolan dicho país". ${ }^{15}$

\section{Pershing contra Villa}

Desoyendo tales pretensiones, Wilson se limitó a presentar las consabidas protestas formales; pero cuando en el mes de marzo los villistas se atrevieron a atacar la población estadounidense de Columbus, aunque lo

13 Duroselle: Política exterior..., pág. 81.

14 Knight: La Revolución Mexicana..., vol. II, págs. 917-918, y Richmond: La lucha nacionalista..., págs. 267-268.

15 El Noticiero Sevillano, sábado 15 de enero de 1916. 
hicieran sin apenas consecuencias, la administración norteamericana cambió de opinión respecto a la intervención que se le estaba demandando. A pesar de que los asaltantes fueron rechazados sin problemas, en ese momento se había sobrepasado el límite de la paciencia de Washington, que decidió responder a la agresión ordenando que una división del ejército, compuesta, contaban los rotativos peninsulares, por "cinco mil hombres al mando del general Tiniston [sic], que fue el que capturó a Aguinaldo en Filipinas", ${ }^{16}$ entrara en México con el fin de detener a Villa. En esta ocasión, como en tantas otras a lo largo del conflicto, la prensa española estaba informada sólo a medias, ya que, como sabemos, tal expedición, conocida como la "expedición Pershing", estuvo dirigida por este último general, y no por el artífice de la captura de Aguinaldo cuyo nombre (Funston), por otra parte, ni siquiera se transcribe bien.

Los estadounidenses declararon que habían informado a Carranza sobre el envío de estas tropas, que contaban con la aprobación de éste para entrar en territorio mexicano, y que el único propósito de la expedición era detener a Villa. Pero los estudiosos del tema afirman que la consulta no se hizo hasta después de que los soldados estadounidenses cruzaran la frontera. Consciente de la imposibilidad de hacer nada para impedirlo, aun en el caso de que la entrada no se hubiera producido ya, el primer jefe terminaría por conceder la autorización que se le pedía. A cambio, exigió algunas contrapartidas que evitaran ponerlo en evidencia ante sus gobernados; entre ellas estaba, al parecer, que los soldados mexicanos pudieran, a su vez, perseguir a los villistas en territorio norteamericano, y que la citada expedición actuara siempre en colaboración con sus tropas; y los Estados Unidos accedieron, al menos en teoría, a ellas. ${ }^{17}$

La expedición terminaría, como sabemos, en un rotundo fracaso, y su estancia en México se prolongaría bastante más de lo que se había previsto, convirtiéndose en permanente fuente de conflictos entre ambas administraciones. Aunque las autoridades de Washington declararan, una y otra vez, que su objetivo no era la invasión del territorio mexicano sino la captura de Villa, al que, decían, entregarían después al "presidente legítimo de Méjico" ${ }^{18}$ su presencia ponía a éste en una situación complicada ante sus

16 Ibídem, domingo, 15 de marzo de 1916. Se trataba de la conocida expedición punitiva de Pershing, aunque la prensa sevillana no informó debidamente de esta cuestión.

17 Richmond: La lucha nacionalista..., págs. 268-269.

18 Ver tanto El Noticiero Sevillano como El Liberal de Sevilla o El Correo de Andalucía de la segunda quincena del mes de marzo de 1916. 
conciudadanos, haciéndolo parecer débil frente a sus vecinos; Villa, por el contrario, pasaba a ser entonces el "héroe" que resistía al invasor. ${ }^{19}$

En ese contexto, los problemas con los militares norteamericanos no tardaron en surgir; muchos de ellos, sin embargo, estarían provocados, al menos en parte, por los propios constitucionalistas, que los utilizarían como justificación ante la opinión pública de su país. Los roces entre los soldados de las dos repúblicas se hicieron tan frecuentes, que las publicaciones sevillanas, como otras muchas españolas e internacionales, comenzaron a especular sobre las condiciones en que los norteamericanos habían entrado en México. En este sentido informaban, aunque sin indicar sus fuentes, que la autorización de Carranza se había concedido sólo para que las tropas "yanquis" ayudaran a las mexicanas a capturar a Villa, pero "dejando" que fueran éstas las que lo detuvieran; y decían, también, que el primer jefe había indicado con claridad que si la expedición se excedía en su misión y originaba "un conflicto internacional", él sabría "defender la dignidad de su patria". ${ }^{20}$

Ese conflicto internacional, afirmaban los medios de comunicación peninsulares, estaba ya a apunto de estallar; por una parte, decían, los soldados constitucionalistas "se mostraban amenazadores" con los estadounidenses, mientras Carranza pedía a Wilson, que hacía caso omiso a sus requerimientos, que los retirara. ${ }^{21}$ Por otra, la expedición tenía que hacer frente también a la hostilidad de la población. Los incidentes con ésta eran casi constantes, y algunos de ellos, como el de El Parral, ocasionaron varias bajas entre el cuerpo expedicionario. Pasaba el tiempo, el objetivo de Washington no se cumplía, y los sentimientos antinorteamericanos en la zona eran cada vez mayores; y, a la vista de que la situación se enrarecía cada vez más, Carranza terminó por "exigir" la inmediata retirada de los soldados estadounidenses, alegando que, a pesar del tiempo transcurrido desde su llegada a México, habían sido incapaces de apresar al caudillo de Chihuahua. ${ }^{22}$

Wilson no parecía dispuesto, sin más, a ello, y propuso iniciar negociaciones sobre el asunto. A su juicio, la retirada no podía hacerse de forma inmediata, como pedían los mexicanos, sino paulatinamente, y siempre que cesaran los ataques de los rebeldes a sus ciudadanos y propiedades. Para

19 Knight: La Revolución Mexicana..., vol. II, págs. 922-923.

20 El Correo de Andalucía, sábado 18 de marzo de 1916.

21 Ibídem.

22 Knight: La Revolución Mexicana..., vol. II, pág. 923. 
muchos observadores, sin embargo, lo que realmente pretendía era que, a cambio de la evacuación de los soldados, Carranza aceptara paralizar las reformas legislativas constitucionalistas que perjudicaban los intereses de su país. El resultado fue que dos meses después de iniciarse las conversaciones en Ciudad Juárez no sólo no se había llegado a acuerdo alguno sobre la cuestión, sino que aquéllas se interrumpieron. Carranza ordenó entonces a su ejército que impidiera cualquier movimiento de los soldados norteamericanos que no tuviera como fin su partida, y que hiciera frente con las armas a cualquier otro destacamento que pretendiera entrar en el país. ${ }^{23}$

Por aquellos días muchos comentaristas internacionales estaban seguros de que se iba a la ruptura de relaciones, especialmente al tener noticias de una supuesta nota de protesta de Carranza en la que, según contaban los diarios, afirmaba que la presencia de las tropas extranjeras era un atentado contra "el honor y la soberanía de México", y pedía, "por última vez", a Woodrow Wilson, que las retirara de inmediato. Real o no, esa nota fue considerada por amplios sectores de la prensa internacional como muy dura e, incluso, descortés, ayudando a acrecentar los rumores de ruptura y de la existencia de algunos "planes" norteamericanos para invadir México. ${ }^{24}$

La supuesta "movilización de la milicia" en los Estados Unidos no hacía sino confirmar, a juicio de las publicaciones conservadoras peninsulares, lo que ellas venían señalando desde mucho antes: que la política norteamericana en México estaba dictada por sus intereses petroleros, que los había llevado, en los primeros momentos de la Revolución, a abrir "las fronteras a la insurrección para que ésta pudiera armarse, y después, desangrado y dividido el país, en nombre de la paz, los sentimientos humanitarios, y de la necesidad de defender a los súbditos extranjeros, anexionarse... lo que convenga......25

Tratando de apoyar esta teoría, que los llevaba a afirmar que en el origen de la caída de Porfirio Díaz se encontraba la intervención estadounidense, esos periódicos hacían un relato de los conflictos que habían enfrentado a ambas naciones, para concluir que todos habían terminado con merma territorial para México. Lo que estaba sucediendo en aquellos momentos no era, para la mayor parte de los comentaristas, sino un paso

23 Ver Richmond: La lucha nacionalista..., pág. 269, y Alessio: Historia política..., 216-217.

24 El Liberal de Sevilla, miércoles 21 de junio de 1916.

25 "Nuestra política en América", La Unión Iberoamericana, Madrid, julio de 1916, pág. 27. Cit. por Delgado Larios, Almudena: La Revolución Mexicana en la España de Alfonso XIII (1910 1931), Junta de Castilla y León, Valladolid, 1993, pág. 284. 
más, tras lo ocurrido con Texas y Nuevo México, en la política expansionista estadounidense. Algunos observadores peninsulares dejaban a un lado los pretendidos deseos territoriales norteamericanos y hablaban sólo de su política de expansión económica; pero, como los anteriores, culpaban también a los Estados Unidos del clima de enfrentamiento que se vivía en México; según ellos, para conseguir el ambiente de seguridad política y jurídica que querían para sus inversiones, habían caído en la contradicción que significaba "multiplicar el desorden" en esa república, para hacer caer un mandatario que ya no les era útil para la mejor marcha de aquéllas. ${ }^{26}$

Por eso, aunque el presidente norteamericano afirmó, una y otra vez, que su país no tenía aspiraciones territoriales en México y que, desde luego, no pensaba en una guerra, gran parte de la prensa internacional, especialmente a raíz de que las tropas de ambas repúblicas protagonizaran una escaramuza en Carrizal, consideraba que ésta era inevitable. La situación, sin embargo, estaba muy lejos de llegar a ese punto. Lo cierto es que, como se dijo más arriba, una parte considerable de los incidentes que se estaban produciendo eran, en cierto modo, artificiales, y originados deliberadamente por los constitucionalistas como forma de presionar a las autoridades estadounidenses para que retiraran sus tropas. Pero siempre se detenían en el límite a partir del cual podría entrarse en un enfrentamiento bélico que, desde luego, no entraba en sus planes.

Son muchos los estudiosos que sostienen que el primer jefe usó repetidamente esta estrategia en sus relaciones con los Estados Unidos, utilizando la "amenaza yanqui" y el incremento de la tensión con aquel país con un doble fin; por una parte, no aparecer ante la ciudadanía como un líder débil frente la injerencia extranjera, y, por otra, conseguir, como había intentado Victoriano Huerta, la unión de todos los revolucionarios contra el enemigo exterior. Sobre la forma de actuar del mandatario mexicano en este sentido, ironizaba, no hace mucho, el conocido escritor mexicano Sealtiel Alatriste, en su novela Conjura en la Arcadia. ${ }^{27}$ Pero ya en su época fue señalada por algunos intelectuales de prestigio de la época, como Vicente Blasco Ibáñez.

26 Ver sobre ello el libro de Carlos Pereyra: Tejas, la primera desmembración de Méjico, Editorial América, Madrid, sin fecha. Ver también "Nuestra política en América", La Unión Iberoamericana, Madrid, julio de 1916, pág. 27. Cit. por Delgado Larios: La Revolución Mexicana..., pág. 284.

27 Sealtiel Alatriste recrea magistralmente las dilaciones carrancistas en sus relaciones con los Estados Unidos, en la citada novela (Tusquets, Barcelona, 2003), centrada en el supuesto secuestro del cónsul norteamericano en Puebla. 
Blasco Ibáñez contaba en sus artículos que cuando Carranza recibía una nota de protesta de sus vecinos, "sonreía..., Ya tenía su incidente y no iba a soltarlo con facilidad. Los diarios del mundo entero hablarían de él durante meses". Para conseguir sus propósitos retrasaba la respuesta hasta el último minuto, para luego dar una tan vaga que ocasionaba una nueva nota cuya contestación volvía a demorar; y así, en una sucesión de réplicas y contra réplicas. Los "periódicos hablaban y hablaban; en los Estados Unidos se hacían suposiciones sobre una guerra posible; en Méjico se daba por segura la intervención". Al final, cuando esa estrategia podía volverse contra él, respondía en un tono adecuado o accedía a lo que se le había pedido; eso sí, entre tanto había hecho creer en su país que se le había exigido mucho más, y que sólo su firmeza había logrado salvar la situación. ${ }^{28}$

Y, efectivamente, no se llegó a ese enfrentamiento armado que la prensa pronosticaba; según las informaciones aparecidas en ella, a comienzos del mes de julio, pensando que ya había tensado la cuerda todo lo que podía, Carranza cedió, en parte, a las pretensiones estadounidenses, comprometiéndose, eso sí vagamente, a no realizar "grandes expropiaciones"; a cambio, Wilson ordenaría, decían los diarios, el regreso de la expedición Pershing. ${ }^{29}$

\section{Hacia el "reconocimiento" definitivo}

La salida de los soldados norteamericanos se demoró, no obstante, considerablemente; pero desde ese momento los incidentes disminuyeron y se volvió a la negociación para resolver los problemas que enfrentaban a las autoridades de ambos lados de la frontera. Y en esta ocasión, aunque se hiciera lentamente, sí se logró avanzar; un mes después de iniciadas las conversaciones los medios de comunicación peninsulares afirmaban que, aunque las diferencias entre las dos administraciones no habían desaparecido, al menos se había llegado a un consenso sobre la manera en que debían tratarse aquéllas; Washington nombraría, como hizo de inmediato, tres representantes, "que con tres mexicanos" formaran la comisión encargada de arreglar las cuestiones pendientes entre ambos. ${ }^{30}$

28 Blasco Ibáñez, Vicente: El militarismo mejicano. Estudios publicados en los principales diarios de Estados Unidos, Editorial Prometeo, Valencia, 1920, págs. 241-246.

29 El Liberal de Sevilla, viernes 7 de julio de 1916.

30 Ibídem, lunes 28 de agosto de 1916. 
Las negociaciones que iniciaron no serían tampoco fáciles ya que, si quería mantener su prestigio en el interior, Carranza no podía ceder en algunos de los puntos que más interesaban a los estadounidenses. Es lo que ocurría, por ejemplo, con la autorización para perseguir a los villistas en territorio mexicano que pedía el gabinete de Washington, consciente de que, como ya había sucedido, podrían atacar algunas de sus poblaciones fronterizas.

El primer protocolo que se presentó al mandatario mexicano sobre esta cuestión, informaba la prensa española, incluía el compromiso de éste de "llamar" a las tropas norteamericanas, en un plazo de cuarenta días a partir de la firma, para que, colaborando con las mexicanas, intervinieran en Chihuahua; su objetivo sería conseguir que las partidas insurrectas dejaran de representar un peligro para las poblaciones del área y, en definitiva, pacificar la zona. Pero una nueva entrada de tropas extranjeras hubiera colocado al mandatario mexicano en una situación comprometida ante su pueblo y, como es lógico, la rechazó. En esta ocasión, sin embargo, probablemente porque, como apuntaban los periódicos, las dos partes estaban interesadas en seguir negociando, "la contestación del general Carranza a la petición de los Estados Unidos para que firme el protocolo", había "sido redactada amistosamente" ${ }^{\prime 31}$ y no en los términos en que solía hacerlo.

Y aunque algunos sucesos, como la detención del "cónsul general" de México en los Estados Unidos, acusado, decían los diarios, "de complicidad en el contrabando de armas y municiones para Veracruz", ${ }^{32}$ dificultaran el proceso, la negociación continuó. Lo cierto es que la estrategia de tensión que tanto gustaba a Carranza estaba dando frutos; tras su rechazo a aquel primer protocolo, Washington terminó por aceptar que el líder constitucionalista no iba a hacer concesiones que pusieran en cuestión la soberanía nacional; en consecuencia, a finales de enero de 1917, los periódicos sevillanos daban cuenta a sus lectores de que el gabinete Wilson había dado, por fin, "las oportunas órdenes", para que la expedición Pershing regresara a su país; ${ }^{33}$ habían pasado seis meses desde que el diario $E l$ Liberal había informado, por primera vez, de la decisión del ejecutivo norteamericano de retirar esas tropas.

La vuelta a la normalidad, sin embargo, no sería bien aceptada por todos; para un sector de la prensa norteamericana, que incluía, entre otras publicaciones, al New York Times, el regreso de la expedición era necesa-

31 Ibídem, lunes 1 y martes 2 de enero de 1917.

32 Ibídem, viernes 5 de enero de 1917.

33 El Noticiero Sevillano, viernes 26 de enero de 1917. 
rio. Se encontraba en el país vecino para "ayudar" a sus tropas a terminar con las incursiones villistas; y como, según ese mismo rotativo, no sólo no lo había conseguido sino que su líder contaba en aquellos momentos "con más de ocho mil hombres" y seguía "reclutando adeptos para atacar a las fuerzas de Carranza", no parecía que hubiera tenido demasiado éxito. En esa situación, además, si las tropas no salían inmediatamente de México corrían peligro de verse envueltas en una verdadera guerra civil. ${ }^{34}$ Pero no todas las publicaciones compartían esa opinión; la orden de retirada no fue demasiado bien vista por algunos grupos de presión, y sus críticas a la administración Wilson, con especial dedicación al propio presidente, encontraron hueco en numerosos medios de comunicación.

Haciéndose eco de esas críticas, los periodistas peninsulares manifestaban que si algunos de sus colegas norteamericanos estaban siendo excesivamente duros con Carranza, del que hablaban como si fuera un simple bandido incapaz de gobernar México, todavía lo estaban siendo mucho más con su propio presidente, al que acusaban de debilidad por no hacer frente al mandatario mexicano con la fuerza apropiada. Según alguno de esos rotativos, lo único que había conseguido Wilson con su falta de energía era el fracaso de la expedición; se había enviado, decían, "contra los generales mejicanos Villa y Carranza", y ambos seguían "en completa libertad" gracias a la política "pusilánime"de su administración, incapaz de hacer nada "ante la guerra de exterminio que llevan a cabo Villa y Carranza", frente a la cual, afirmaban, "todos los mexicanos deben cerrar los ojos y abandonar el territorio nacional". ${ }^{35}$

Dejando en evidencia la poca seriedad de tales comentarios, aunque los asaltos de las tropas villistas continuarían hasta la presidencia provisional de Adolfo de la Huerta en 1920, lo cierto es que la actividad bélica disminuyó considerablemente en la zona fronteriza y que, en consecuencia, las relaciones bilaterales ofrecieron un panorama mucho más tranquilo desde comienzos de 1917; y, según informó la prensa española, en febrero de ese año el departamento de Estado norteamericano enviaba un nuevo diplomático, "Fletcher", para que actuara "como árbitro en las cuestiones aún pendientes entre el gobierno de Washington y Méjico". ${ }^{36}$

34 El Correo de Andalucía, miércoles 31 de enero de 1917.

35 Sobre esas críticas, ver las referencias aparecidas en El Liberal de Sevilla del viernes 19 de enero de 1917 y en El Noticiero Sevillano del sábado 20 del mismo mes y año.

36 Ver los ejemplares de El Liberal de Sevilla del jueves 18 de enero de 1917, del domingo 28 del mismo mes y año, y del viernes 2 de febrero del mismo año. 
Se trataba, sin embargo, de algo más que eso; Henry P. Fletcher no iba a México como un negociador más, sino como embajador en un país considerado ya "amigo" por Washington. Los propios medios de comunicación que lo habían presentado como un simple negociador, publicaban al día siguiente lo que ofrecían como "las últimas noticias recibidas de Nueva York" sobre las relaciones mexicano estadounidenses: que el gabinete de Wilson había reconocido definitivamente a Carranza como jefe del Estado mexicano y que, en consecuencia, había nombrado ante él un nuevo embajador, con el objeto de normalizar "las relaciones diplomáticas", rotas, decían, desde 1914. ${ }^{37}$ También se equivocaban en cuanto a esto ya que, como vimos, en 1915 los Estados Unidos habían aceptado ya al gobierno constitucionalista, aunque sólo fuera como "gobierno provisional" de la República.

De todos modos, los problemas entre ambos gobiernos no desaparecerían con el reconocimiento definitivo a Venustiano Carranza; por una parte, la violencia en la zona fronteriza no desapareció por completo; y, por otra, las inversiones extranjeras se estaban viendo afectadas por la legislación que se estaba poniendo en marcha en México. Por lo que se refiere al primer punto, aunque Villa se encontrara debilitado, continuaba en armas; utilizando fuentes estadounidenses, los periódicos españoles hablaban de lo que llamaban "furiosos ataques en Chihuahua", a la vista de los cuales, afirmaban recogiendo rumores que circulaban tanto por la capital mexicana como por Washington, el general Pershing, "en contra de lo acordado" entre ambos países, había ordenado "suspender la retirada de sus tropas y vigilar las fronteras". "En las esferas oficiales yanquis", añadían, aumentaba la preocupación por la posibilidad de que tuvieran lugar "nuevos desórdenes" o, incluso, por que se produjera un "ataque contra los Estados Unidos". 38

Dando mayor fuerza a ese rumor, algunas informaciones procedentes de Texas indicaban que "cinco mil soldados de Villa, con éste a la cabeza", habían tenido ya algún "encuentro con las tropas Yankis" en aquella zona. ${ }^{39}$ $\mathrm{Y}$ aunque esos rumores no tuvieron confirmación oficial, lo cierto es que las publicaciones sevillanas se hicieron eco de algunos enfrentamientos armados en los que, en ocasiones, aparecían implicados soldados estadou-

37 El Liberal de Sevilla, sábado 3 de febrero de 1917.

38 El Correo de Andalucía, domingo 11 de febrero de 1917, y El Liberal de Sevilla del martes 13 del mismo mes y año.

39 El Correo de Andalucía, viernes 19 de febrero de 1917. 
nidenses, algo digno de destacar si tenemos en cuenta que, al menos en teoría, la expedición Pershing tenía que haber salido ya de territorio mexicano. Como muestra de ello, los medios de comunicación hablaban de uno de esos incidentes, ocurrido "cerca de Nogales", donde "unos bandidos" atacaron a las tropas norteamericanas que, tras hacer varios prisioneros, habían logrado rechazarlos sin bajas..$^{40}$

Muy poco después contaban también, que una partida de cuarenta hombres pertenecientes a "las tropas del general Villa", tuvieron un "encuentro" con "una patrulla de caballería yanqui", que habría terminado con la muerte de algunos de aquéllos. ${ }^{41}$ Pero se trataba ya de incidentes aislados que no justificaban que Washington tomara medidas que, a la larga, podían resultar peligrosas.

Mayor inquietud provocarían en los Estados Unidos las reformas legislativas que pretendían los constitucionalistas e, incluso, los propios debates que originaron la aprobación de la Constitución de 1917. Con motivo de esos debates, en Washington se decía que el propósito de las nuevas autoridades mexicanas era, simplemente, actuar contra sus intereses, comenzando por la incautación de "los pozos de petróleo sin explotar" que estuvieran en manos extranjeras, para avanzar después hacia otras expropiaciones. ${ }^{42}$

\section{La Guerra Europea y las presiones diplomáticas}

Aunque tanto este temor como los incidentes fronterizos causaban fricciones entre las autoridades de los dos lados de la frontera, ambos problemas pasarían a ser, no obstante, cuestiones menores, en unos momentos en que las verdaderas tensiones vendrían provocadas por la posición de México ante el conflicto europeo. El gobierno de Venustiano Carranza, que siempre buscó alianzas exteriores que permitieran contrarrestar la excesiva influencia de los norteamericanos en México, declaró su neutralidad desde los primeros momentos de la contienda. Esa declaración le valió ser acusado de germanófilo en amplios sectores sociales y políticos del país vecino, no sin cierto regocijo entre los conservadores españoles, como se aprecia con sólo echar un vistazo a los periódicos de esa ideología. No es que el

40 El Liberal de Sevilla, jueves 24 de mayo de 1917.

41 Ibídem, sábado 16 de junio de 1917.

42 El Correo de Andalucía, miércoles 21 de febrero de 1917. 
rechazo a la intervención norteamericana en México se diera sólo en un sector de la prensa ya que, como se ha dicho, fue algo general desde el principio del movimiento revolucionario. Pero es que, en este caso, la problemática se vio afectada, además, por el debate entre aliadófilos y germanófilos que tenía lugar entonces en la sociedad española, y que tuvo amplio eco en los distintos diarios.

En este sentido, es representativo el título - "A Wilson le ha salido un grano"- con el que El Correo de Andalucía abría su información sobre la supuesta cercanía del gobierno mexicano al bando alemán. El hecho de que "trescientos reservistas alemanes" hubieran llegado a México para colaborar con sus autoridades, impidiendo un supuesto "desembarco yanki en Tampico con el fin de apoderarse de los pozos de petróleo", era sólo una muestra, decían, de las simpatías del mandatario mexicano. ${ }^{43}$

Aunque esa información nunca fue confirmada, lo cierto es que los alemanes desplegaban una intensa actividad diplomática en México, y que los Estados Unidos, conscientes de la hostilidad que habían despertado allí con su actuación, no parecían estar demasiado tranquilos al respecto ${ }^{44}$ Los rotativos de todo el mundo se hacían eco de la preocupación que existía en los "centros oficiales norteamericanos", ante los intentos alemanes de involucrar a México en el conflicto europeo. Prueba de esa preocupación, indicaban los diarios, era su denuncia ante las "repúblicas americanas" de lo que llamaron "complot" de los alemanes en México, y de su petición de ayuda a aquéllas para conseguir que el gabinete de Carranza se inclinara por el bando aliado..$^{45}$

Las publicaciones españolas contaban que, según informaciones procedentes de Washington, oficiales alemanes instruían al ejército mexicano, "particularmente realizando prácticas de aviación"; a cambio, sus submarinos se abastecían allí y se preparaban para detener la "exportación de aceites de América a Inglaterra". ${ }^{46} \mathrm{Y}$ añadían que Wilson, preocupado por ello, había remitido una nota al presidente mexicano, haciéndolo "responsable... de cuantos acontecimientos perjudiciales para la dignidad de los Estados Unidos se desarrollen en Méjico". ${ }^{47}$ La supuesta nota aludía, al parecer, al

43 Ibídem.

44 Para una visión detallada de la problemática, ver Katz, Friederich: La Guerra Secreta en México. Europa, Estados Unidos y la Revolución Mexicana, Ediciones Era, México, 1982.

45 El Noticiero Sevillano, viernes 9 de marzo de 1917, El Liberal de Sevilla del viernes 2, sábado 3, y domingo 4, y El Correo de Andalucía del sábado 3 del mismo mes y año.

46 El Correo de Andalucía, domingo 11 y lunes 12 de marzo de 1917.

47 El Noticiero Sevillano, lunes 12 de marzo de 1917. 
temor por lo que pudiera ocurrir en Tampico, donde los responsables de los pozos de petróleo habían pedido protección a las fuerzas norteamericanas, convencidos de "que los alemanes procurarán incendiarlos para que se rompan las relaciones entre los Estados Unidos y Méjico". ${ }^{48}$

También en este último país corrían fuertes rumores sobre la posición de Carranza en la contienda europea. Recogiendo algunos de ellos, los rotativos peninsulares afirmaban que, "en caso de que estalle la guerra entre los Estados Unidos y Alemania", Carranza podía abandonar su supuesta neutralidad. Y aunque no informaban claramente en qué sentido lo haría, sí indicaban que los agentes alemanes estaban haciendo "supremos esfuerzos" para que fuera a favor de su país. ${ }^{49}$ De nada servían las repetidas declaraciones de las autoridades mexicanas reafirmando su neutralidad. En toda Europa se especulaba sobre la "alianza germano-mejicana" aunque, en ocasiones, esas especulaciones resultaran contradictorias. ${ }^{50}$

La falta de fuentes fiables sobre el asunto haría surgir rumores disparatados; parte de ellos, como el que señalaba que en algunos círculos militares norteamericanos se hablaba, incluso, de un posible ataque mexicano "contra los Estados Unidos", fueron recogidos por los diarios españoles. La prensa sevillana, confusa, como tantas otras veces a lo largo del proceso revolucionario, no tenía, sin embargo, nada claro, si ese ataque vendría "del ministro de guerra mexicano" o de "los generales Obregón o Villa", ignorando que mientras el primero de los caudillos citados estaba, todavía - aunque abandonara su cargo en la Secretaría de Guerra—, en el bando constitucionalista, Villa se había declarado en rebeldía hacía tiempo.

Pero lo que sí tenían claro los rotativos era el empeño alemán por conseguir apoyos en México. Preferían contar, decían, con el del gobierno; pero si éste no llegaba estaban dispuestos a aceptar el de Villa. En esta línea, algunos telegramas recibidos desde El Paso, y que eran recogidos en sus páginas, daban cuenta del "recrudecimiento de la actividad" de los villistas que, "mandados por reservistas alemanes", se preparaban para marchar contra los Estados Unidos, ${ }^{52}$ algo que no sería sino uno de los muchos rumores surgidos al amparo de la falta de noticias más fiables.

48 El Correo de Andalucía, miércoles 14 de marzo de 1917.

49 Ver El Liberal de Sevilla del jueves 8 y viernes 9 de Marzo de 1917.

50 Ver El Correo de Andalucía, domingo 4 de marzo de 1917, y El Noticiero Sevillano del lunes 5 del mismo mes y año.

51 El Liberal de Sevilla, martes 13 de febrero de 1917.

52 Ibídem, domingo 8 de abril de 1917. 
Hablaban también esos días de que, a la vista de los "manejos" de los alemanes, Wilson había remitido al mandatario mexicano una nueva nota, que no dudaban en calificar como "preliminares de ultimátum", en la que le pedía que expulsara del país al ministro alemán, porque su actividad representaba "un peligro para la tranquilidad de la república yanki". ${ }^{53}$

Consciente de que si quería gobernar sin excesivos sobresaltos debía conjurar la posibilidad de una nueva intervención norteamericana, Carranza intentó acabar con la riada de murmuraciones, aclarando, de una vez por todas, las directrices de su política exterior. Y lo haría, según afirmó la prensa sevillana, "en la apertura del Parlamento" que se inauguró una vez aprobada la Constitución. Ante esa cámara, el primer jefe afirmó, rotundamente, que observaría "una neutralidad rigurosa en el conflicto mundial"; 54 y lo mismo harían, en los días siguientes, sus diplomáticos destacados en el extranjero. En el caso de España, el representante mexicano en Madrid trasladó a los medios de comunicación "un cablegrama de su gobierno", en el que éste reiteraba su propósito "de seguir observando neutralidad". ${ }^{55}$

No por ello cesarían los rumores, más o menos interesados, sobre el asunto; no obstante, también comenzaron a surgir otros en sentido contrario. Algunos medios de comunicación internacionales, incluidos algunos sevillanos, afirmaban que México no mantendría su posición de neutralidad; pero no porque su presidente decidiera apoyar a Alemania como se venía diciendo, sino porque, por el contrario, terminaría aliándose "con las potencias de la Entente" ${ }^{56}$ Por otro lado, sucesos tan al margen del problema como la renuncia de Obregón a la Secretaría de Guerra daban pie a todo tipo de especulaciones; algunos comentaristas llegarían a ver en su dimisión, como hemos comprobado, no sólo el propósito del general de sublevarse contra Carranza, sino también el de "ponerse al frente de una expedición contra los Estados Unidos, apoyada por Alemania". ${ }^{57}$

Aparentemente ajeno a esos rumores, el primer jefe se mantuvo firme a pesar de las presiones internacionales para que modificara su postura, presiones que se incrementarían considerablemente cuando, finalmente, los Estados Unidos entraran en la guerra europea e, insatisfechos con una neu-

53 El Correo de Andalucía del miércoles 11 y sábado 14 de abril de 1917.

54 El Liberal de Sevilla, martes 17 de abril de 1917, y El Correo de Andalucía del día siguiente.

55 Ibídem, sábado 21 de abril de 1917.

56 El Correo de Andalucía y El Liberal de Sevilla del martes 1 de mayo de 1917.

57 El Liberal de Sevilla, sábado 5 de mayo de 1917. 
tralidad que podía quebrarse en cualquier momento, redoblaran sus esfuerzos para incorporar a México a su causa. Además, esas presiones se harían también desde algunos sectores mexicanos. La prensa sevillana, recogiendo noticias aparecidas en algunos diarios estadounidenses, contaba a sus lectores que "las Cámaras mejicanas" iban a "pedir al gobierno" que declarara "una neutralidad benévola para los Estados Unidos y sus aliados".

Según esas mismas fuentes, mientras los alemanes ponían "todos sus medios en juego" para impedirlo, los rotativos norteamericanos descalificaban lo que llamaban "campañas" de los alemanes y celebraban el texto que, supuestamente, pretendían aprobar los parlamentarios mexicanos, calificándolo como "un llamamiento a la conciencia mejicana, para que no permanezca indiferente a la gigantesca tragedia que se desarrolla en el mundo". Pretendiendo ganarse las simpatías mexicanas, los diarios norteamericanos elogiaban en sus páginas, por primera vez desde el inicio de la Revolución, al país vecino, del que decían que "honrando su pasado y sus ideales", debía "estar al lado de aquellas naciones que combaten por la justicia, la civilización y la libertad". ${ }^{58}$

Indiferente tanto a los halagos como a las presiones, y a pesar de que algunas informaciones señalaban que era "inminente la ruptura de relaciones" de México con Alemania, ${ }^{59}$ Carranza no varió un ápice su postura que, desde luego, no fue entendida por muchos, y que le valió seguir recibiendo acusaciones de germanófilo; pero el gabinete de Washington, contando, probablemente, con garantías que la prensa desconocía, se desentendió, al menos en apariencia, de los asuntos mexicanos, mientras participaba en la guerra europea.

\section{Entre la diplomacia y el enfrentamiento}

El interés por el "problema mexicano" retornaría, sin embargo, con el fin de aquélla; y con él volverían también los choques entre ambas administraciones, ocasionados, en su mayor parte, por las consecuencias de la legislación que había ido naciendo de la Constitución de 1917. Aunque las explicaciones que se dieran en cada caso fueran distintas, y a pesar de que se utilizaran diferentes pretextos para justificar determinadas actuaciones,

58 Ibídem, viernes 26 de octubre, de 1917.

59 El Noticiero Sevillano, miércoles 24 de octubre de 1917. 
el origen de casi todos los problemas estaba en esa legislación y en la propia Carta Magna, cuyo artículo 27 declaraba el subsuelo propiedad nacional. Hay que tener en cuenta que a comienzos de la Revolución el capital norteamericano controlaba el $78 \%$ de la industria minera mexicana, el $72 \%$ de las fundiciones, el 58\% de las empresas petroleras, y el $70 \%$ de las inversiones realizadas en ferrocarriles. En consecuencia, tanto la propia Constitución - muy especialmente el artículo citado - como las medidas legislativas emanadas de ella fueron duramente contestadas por los inversores estadounidenses que, además, no dejaron de presionar a su gobierno para que los apoyara frente a la administración carrancista. ${ }^{60}$

La actitud de las compañías petroleras desde que se aprobó la Carta Magna sería, en este sentido, una de las principales fuentes de tensión. Durante los diez años siguientes se opusieron con todos los medios posibles a las nuevas normativas legales, aunque éstas no afectaran directamente a la propiedad. Así, cuando en febrero de 1918 las autoridades mexicanas emitieron un decreto que incrementaba, de forma progresiva, los impuestos sobre la perforación y la producción de petróleo, y autorizaba la confiscación de las explotaciones que no los pagaran, las empresas, contando con la ayuda de su gobierno para hacer frente al mexicano, se negaron a hacerlo. La administración norteamericana no sólo presentó la correspondiente nota de protesta a la mexicana, sino que, según algunos autores, el secretario de Estado llegó a barajar la posibilidad de enviar tropas a México para ocupar los pozos; no obstante, la situación en Europa demandaba todavía la atención estadounidense y si aquel proyecto era cierto, no llegó, afortunadamente, a realizarse.

Pero con el fin de la guerra europea, como se ha dicho, los Estados Unidos se vieron más libres para actuar en defensa de los intereses de sus inversores en México y, por lo tanto, los afectados tuvieron menos dudas a la hora de hacer frente a las autoridades autóctonas, contribuyendo con sus actuaciones a enrarecer el clima de entendimiento. La rebeldía de los empresarios a los decretos carrancistas fue constante, y alcanzó su punto máximo cuando, en 1919, iniciaron nuevas perforaciones sin contar con la autorización que marcaban las leyes; se ponía en entredicho la autoridad del gobierno mexicano, y éste se vio obligado a enviar tropas para detener la actividad, llegándose con ello al borde de la guerra. ${ }^{61}$

60 Para esta decisiva problemática ver Meyer, L.: México y los Estados Unidos en el conflicto petrolero. 1917-1942, El Colegio de México, México, 1991.

61 Richmond: La lucha nacionalista..., págs. 272-273. 
La gravedad de estas cuestiones pasaba desapercibida, no obstante, para la prensa española; la única información sobre el sector que apareció en las páginas de los diarios sevillanos en los meses inmediatamente posteriores a la aprobación de la Carta Magna fue una breve alusión a una huelga que tuvo lugar a mediados de 1917 en los pozos de Tampico, en la que, decían, habían participado "quince mil" obreros. ${ }^{62}$ A lo largo de todo ese año comentaron en sus páginas que existían graves dificultades para la vuelta a unas relaciones más o menos normales entre ambos países; pero las achacaron a la situación de inestabilidad que, según ellos, se vivía en la frontera, con una supuesta intensificación de los ataques villistas.

Los rotativos peninsulares decían, en este sentido, que ante "los graves sucesos" ocurridos allí entre el 15 y el 24 del mes de agosto de 1919, sucesos que no detallaban, el presidente Wilson había decidido hacerse "cargo personalmente de la dirección de los asuntos con Méjico". ${ }^{3} \mathrm{El}$ resultado de ello fue el envío de un destacamento de caballería estadounidense al otro lado de la frontera, con la consiguiente protesta del gabinete mexicano por la violación del territorio de su país y la subida de un nuevo peldaño en la escalada de tensión. Pero, en una aparente contradicción, este incidente sirvió, decían algunas publicaciones, para que las autoridades mexicanas, con el fin de terminar de una vez por todas con las disputas con sus vecinos, iniciaran en serio "la caza de los bandidos que buscan refugio en la frontera". ${ }^{64}$

Entre tanto, consciente de que fuera de México se ignoraba el origen de su contencioso con los Estados Unidos, que propagaban internacionalmente su propia versión, interesada desde luego, de aquél, y en la que se daba una imagen nada favorable del país y de sus dirigentes, Carranza intentaba neutralizar el efecto de los comunicados de prensa de sus vecinos. Siempre había mostrado su preocupación por la imagen de la República en el exterior; muestra de ello fueron las "misiones divulgativas" que envió a Europa ya desde el momento en que se sublevó contra Victoriano Huerta. Esa labor de propaganda se había visto interrumpida por la guerra europea; y cuando ésta terminó no tardó en reanudarla. Como primer paso para ello, informaban los periódicos españoles, envió una emba-

62 El Noticiero Sevillano del viernes 27 de julio de 1917.

63 El Liberal de Sevilla, sábado 23 de agosto de 1919. siguiente.

64 El Correo de Andalucía, sábado 23 de agosto de 1919, y El Liberal de Sevilla del día 
jada a París, "con objeto de capturar las simpatías de Francia a favor de Méjico", y otra a Londres, destinada al restablecimiento de relaciones. ${ }^{65}$

En esta misma línea, tras la crisis desatada por la nueva entrada de tropas norteamericanas en México, y ante la deformada visión que se tenía en Europa de semejantes acciones, decidió remitir a España otra de esas misiones, "portadora de un documento relativo al conflicto entre México y los Estados Unidos". Su fin, decían los diarios peninsulares, era ofrecer su versión sobre la problemática "a los gobiernos europeos" ${ }^{66}$ en cuyos países seguían circulando, todavía, los rumores sobre su simpatía con Alemania. ${ }^{67}$

Sus esfuerzos se verían dificultados, sin embargo, por algunos incidentes que afectaron a ciudadanos norteamericanos, el más conocido de los cuales quizás sea el oscuro episodio del supuesto secuestro del cónsul norteamericano en Puebla, William O. Jenkins. El suceso fue muy "sonado" en su momento, y mostrando, una vez más, la pervivencia de la Revolución a través de medios como la narrativa o el cine, ha sido recreado recientemente por Sealtiel Alatriste en su novela, ya citada, Conjura en la Arcadia.

En octubre de 1919 tenía lugar ese supuesto secuestro a manos, aparentemente, de "una banda revolucionaria" que pidió el correspondiente rescate. Los Estados Unidos consideraron responsable del mismo a la administración mexicana, a la que exigieron el pago de aquél. Carranza no sólo no accedió a ello, sino que ni siquiera pareció demasiado inquieto por el asunto. Lo peor, no obstante, estaba por llegar. Sin que nadie llegara a saber cómo se había llegado a su liberación, Jenkins apareció; y las sospechas, bastante justificadas por otra parte, sobre la veracidad de su retención que, según él, sólo terminó cuando él mismo pagó el rescate que habían pedido sus captores, fueron inevitables.

El asunto no terminaría ahí porque, de inmediato, fue detenido por las autoridades mexicanas bajo la acusación de haber participado en un falso secuestro, que formaría parte, alegaron, de una amplia conspiración destinada a desprestigiar el carrancismo ${ }^{68}$ El gobierno de Washington exigió su inmediata liberación, a lo que los dirigentes mexicanos respondieron que Jenkins estaba preso "por un asunto que está sometido al fallo de las autoridades judiciales" y que, por tanto, nada podían hacer al respecto. El gabi-

65 El Liberal de Sevilla, viernes 13 de junio de 1919.

66 Ibídem, domingo 31 de agosto de 1919.

67 Ver, por ejemplo, El Correo de Andalucía del 26 de agosto de 1919.

68 Cline, Howard F.: The United Satates and Mexico, Cambridge, Harvard University Press, 1967, págs. 190-191, y Richmond: La lucha nacionalista..., pág. 273. 
nete Wilson fue convocado a una reunión de urgencia para tratar la cuestión; y aunque las publicaciones españolas reconocían desconocer lo que se había decidido en ella, afirmaban que, según todas las noticias que se recibían de allí, "los departamentos de guerra y marina" estaban preparados para "toda eventualidad". 69

Y no fue éste el único caso que, además de oscurecer la campaña propagandística de Carranza, dificultó las relaciones con los Estados Unidos. En la zona fronteriza se multiplicaban los incidentes que afectaban a ciudadanos norteamericanos, y los Estados Unidos pedían reparaciones por ellos. Es lo que ocurrió, por ejemplo, con la muerte "del súbdito americano Wallace", una de las víctimas de las bandas rebeldes, que llevó a Wilson, aseguraban los periódicos, a exigir a las autoridades mexicanas "el castigo del asesino", y a amenazar con romper las relaciones diplomáticas, dejando "de reconocer", en caso contrario, "al gobierno de Carranza". Al mismo tiempo, se difundían una serie de rumores sobre esos incidentes, que indicaban que los ataques a estadounidenses no siempre eran realizados por partidas rebeldes; según algunos de ellos, "varios soldados del ejército de Carranza" habían "matado a un soldado yanqui". ${ }^{70}$

Se decía, también, que ante tal estado de cosas Pershing había "recibido la orden de ir", de nuevo, "a la frontera mejicana", en teoría, para "inspeccionar las tropas que hay allí"; pero eran muchos los que pensaban que Wilson estaba preparando una nueva intervención. Otras informaciones señalaban, sin embargo, que aunque a la vista de los atentados cometidos contra ciudadanos de su país "los miembros republicanos de la comisión senatorial" habían pedido al presidente "la urgente ruptura de relaciones", éste no se mostraba partidario de llegar a tales extremos. Por una parte, el acuerdo del gobierno mexicano de liberar al "vicecónsul Jenkins a cambio de 200 dólares" hizo bajar la tensión algunos grados; por otra, la enfermedad del presidente norteamericano, decían los diarios, había hecho que se detuviera 0 , al menos, que se aplazara, cualquier respuesta violenta. ${ }^{71}$

En esta ocasión, a diferencia de otra muchas como hemos visto, lo que transmitía la prensa española no se alejaba demasiado de la realidad; como decía aquélla, en el Senado se había presentado una petición de ruptura con México, que no sería sino el primer paso para una declaración de guerra.

69 El Liberal de Sevilla, viernes 28 de noviembre y martes 2 de diciembre de 1919.

70 Ibídem, martes 2 de diciembre de 1919.

71 Ver El Correo de Andalucía del lunes 8 de diciembre de 1919, y El Liberal de Sevilla del mismo día, así como el del martes 2 del mismo mes y año. 
Una delegación de esa cámara visitó a Wilson, que, efectivamente, estaba enfermo, intentando que asumiera sus pretensiones. Pero la noticia de la liberación de Jenkins pesó en el ánimo de éste, que, haciendo caso omiso a las presiones, decidió aplazar cualquier medida militar, manteniendo las conversaciones secretas que se desarrollaban paralelamente, y que pensaba podían darle mejor resultado. Como siempre, cuando la situación parecía haber llegado al límite Carranza había cedido, al menos en parte, excarcelando a Jenkins y concediendo algunos nuevos permisos de perforación petrolífera; pero con sus tácticas dilatorias había logrado a cambio que los norteamericanos terminaran por reconocer el derecho de su país a establecer su propia política petrolera. ${ }^{72}$

\section{Epílogo: el fin de un mandatario "incómodo"}

Las relaciones entre los dos países parecían entrar en una vía de relativa normalidad cuando la rebelión sonorense, de la que Álvaro Obregón terminaría por ponerse al frente, pondría de nuevo a todos en situación de alerta. El gobierno estadounidense, decían los diarios, ordenó "que varios contratorpederos" marcharan a Veracruz y Tampico "para proteger la vida de los soldados yanquis, recogiéndolos a bordo, así como a cuantos extranjeros estuvieran en peligro". Con una nueva revuelta de consecuencias imprevisibles, la administración Wilson dispuso, además, "que un acorazado yanqui" y "mil doscientos fusileros" salieran hacia aguas mexicanas, probablemente, contaban los rotativos, "para efectuar un desembarco". ${ }^{73}$

De nada sirvieron las opiniones del representante norteamericano en México, contrario a unas medidas que, a su juicio, sólo podían ocasionar incidentes con un ejecutivo al que se había reconocido oficialmente y con el que se mantenían relaciones diplomáticas. ${ }^{74}$ El gobierno de Washington, pensando, probablemente, que la victoria de los sublevados podría representar un giro favorable para ellos en lo que consideraban excesivo nacionalismo de la política constitucionalista, no jugó, a juicio de algunos observadores, con demasiada limpieza en este asunto.

Su posición en aquellos momentos, desde luego, no estuvo clara para muchos; casi todas las informaciones que llegaban del otro lado del

72 Cline: The United States..., págs. 191-192, y Richmond: La lucha nacionalista..., pág. 274.

73 El Liberal de Sevilla, miércoles 5 y jueves 13 de mayo de 1920.

74 Ibídem, viernes 14 de mayo de 1920. 
Atlántico señalaban que no sólo no se mostraba preocupado por el que parecía seguro triunfo de los rebeldes, sino que, según algunos rotativos españoles, daba la impresión de que apoyaba la insurrección. El Liberal de Sevilla decía, en este sentido, que "en los centros oficiales yanquis" se afirmaba "que el ministerio de Estado no tendría escrúpulos en negociar con el general Obregón si se comprobaba" la derrota de Carranza. ${ }^{75}$

Al margen de que ese apoyo fuera cierto o no, las relaciones entre ambos países mejoraron tanto con el triunfo de los sublevados, que algunos periódicos llegaron a afirmar que Washington había "reconocido al presidente de la república mejicana", aunque todavía no tuvieran claro de quién se trataba y señalaran como tal al "general Herrera". ${ }^{76}$ No era así, desde luego; pero la situación económica con que se encontraron las nuevas autoridades las obligó a ceder, finalmente, en algunos de los puntos planteados por el gobierno norteamericano que Carranza había considerado innegociables.

La prensa informaba sobre este asunto que el secretario de Hacienda del gobierno provisional, "el general Alvarado", negociaba con los Estados Unidos un préstamo "de ochenta millones de libras", para cuya obtención estaba ofreciendo a los banqueros condiciones similares "a las concedidas por el ex presidente Porfirio Díaz en un empréstito semejante", ${ }^{77}$ en lo que no sería, para ella, sino un paso atrás en la política nacionalista de Venustiano Carranza. En esa misma línea, los medios de comunicación de la capital andaluza recogían otras noticias que inducían a sospechar un posible acuerdo entre los rebeldes y la administración Wilson, a la que, apuntaban, aquéllos habrían tranquilizado en cuanto al futuro de las inversiones extranjeras.

Algunos diarios informaban, en este sentido, que "el presidente interino" nombrado por los insurrectos, Adolfo de la Huerta, había "invitado a los súbditos extranjeros" a que depositaran "sus fondos en los bancos mejicanos". ${ }^{78}$ Daban cuenta, también, de que los revolucionarios habían convocado una reunión "con los directores" de varias compañías petroleras, para pedirles, en nombre del gobierno provisional, "un anticipo de 500.000 libras esterlinas para hacer frente a la situación". ${ }^{79}$ Para ellos era evidente

\footnotetext{
75 Ibídem, jueves 13 de mayo de 1920.

76 El Correo de Andalucía de 26 de junio de 1920.

77 El Liberal de Sevilla, sábado 28 de agosto de 1920.

78 Ibídem, viernes 7 de mayo de 1920.

79 Ibídem, domingo 16 de mayo de 1920.
} 
que si los sublevados pretendían conseguir apoyo financiero de los petroleros, tenía que ser a cambio de algunas cesiones a las que Carranza se había negado.

Lo cierto es que para un sector importante de la prensa española, y desde luego para la sevillana, tanto Adolfo de la Huerta como Álvaro Obregón se mostraron mucho más dispuestos que Carranza a negociar con las empresas petroleras, que desde hacía tiempo venían desafiando al gobierno mexicano. Comenzaron por comprometerse a "estudiar" con tranquilidad algunas medidas que afectaban al sector, como la subida de impuestos sobre la exportación de petróleo que pretendieron imponer a comienzos de $1921,{ }^{80}$ y terminaron por llegar, en septiembre del mismo año, "a una avenencia" con aquéllas — no se especificaba en qué términos-, que "permitiría reanudar la explotación de los pozos de petróleo". ${ }^{81}$

A pesar de ello $-\mathrm{y}$ probablemente algo tuvo que ver en la cuestión la muerte violenta de Carranza-, los Estados Unidos nunca llegaron a reconocer al gobierno provisional encabezado por de la Huerta; y, durante el mandato de Wilson, tampoco al posterior presidente electo Álvaro Obregón. Además, y pese a las sospechas de la prensa extranjera ya señaladas sobre el supuesto apoyo estadounidense a los sublevados, los problemas económicos seguirían produciendo, como en la etapa carrancista, importantes enfrentamientos entre las autoridades de ambos países. Por mucho que desearan el entendimiento con sus vecinos, algunas de las condiciones que Washington ponía para reconocer al nuevo ejecutivo, entre ellas, la anulación total de lo que llamaba "legislación confiscatoria" de Carranza, no podían ser aceptadas por los mexicanos. ${ }^{82}$

Pero parece evidente que, como señalaba la prensa sevillana, los sucesores del primer jefe fueron mucho más flexibles que él a la hora de negociar con sus vecinos; y que aunque los Estados Unidos no consiguieran terminar con la legislación que perjudicaba a sus intereses, aprovechándose de la difícil situación financiera por la que atravesaba México, lograron ventajas que le habían sido negadas por aquél, y que serían sancionadas por la firma de los acuerdos de Bucareli en 1923. Por ese acuerdo, decía la prensa española, los Estados Unidos reconocían al gobierno de Obregón que,

80 El Correo de Andalucía, viernes 28 de enero de 1921.

81 Ibídem, miércoles 14 de septiembre de 1921.

82 Castro Martínez, Pedro: Adolfo de la Huerta y la Revolución Mexicana, Instituto de Estudios Históricos de la Revolución Mexicana, México, 1992, pág. 61. 
por su parte, se comprometía a no aplicar la legislación sobre el petróleo de manera retroactiva, sacrificando así principios que eran considerados por muchos como esenciales para el nacionalismo mexicano. ${ }^{83}$

\section{Conclusiones}

En definitiva, como hemos visto, la prensa española y, por supuesto la sevillana, que, en general, parecía sentir más simpatía por Venustiano Carranza que por otros líderes de la Revolución mexicana demasiado radicales para ella, como Villa, o más "complacientes" con las inversiones estadounidenses, como Obregón, ofreció a sus lectores una visión parcial y limitada sobre sus relaciones con los vecinos del norte, aunque poco tuviera que ver en ello la ideología de cada periódico.

Los utilizados como fuente básica para este trabajo ( $\mathrm{Cl}$ Correo de Andalucía, El Noticiero Sevillano y El Liberal de Sevilla) representaban en aquellos momentos las posiciones de distintos sectores ideológicos y políticos de la sociedad (conservador-católico el primero, monárquico el segundo y republicano el tercero). Pero todos tenían algo en común: su visión de las relaciones entre los Estados Unidos y la administración carrancista estuvo más determinada por la preocupación por los intereses de los españoles residentes en México y por su rechazo al "imperialismo yankee" que por sus principios ideológicos. ${ }^{84}$

Serán otras, pues, las causas de que esa visión fuera incompleta y parcial. Por una parte, la falta de fuentes fiables sobre lo que estaba sucediendo en ese campo y el lógico deseo de ofrecer las noticias a sus lectores cuanto antes llevó a los distintos diarios a suministrar informaciones erróneas, como hemos indicado, y a especular sobre determinadas actuaciones de unos y otros. Y, al mismo tiempo, a reflejar en sus páginas algunos incidentes sin importancia real para la marcha de las relaciones bilaterales, obviando otros que, en cambio, resultaron fundamentales para aquéllas. En este sentido es curioso el hecho de que, si bien a la hora de editorializar, las distintas publicaciones, y especialmente las más conservadoras, nunca dejaron de señalar que en el fondo de los problemas bila-

83 Ver sobre ello el editorial "Méjico y los Estados Unidos", publicado en El Sol de Madrid el viernes 6 de julio de 1923. Cit. por Delgado Larios: La Revolución Mexicana..., págs. 290-291.

84 Sevilla Soler, R.: La Revolución Mexicana..., págs. 235-241. 
terales estaba la cuestión del petróleo y, en definitiva, la marcha de los negocios estadounidenses en México, las informaciones que nos trasladan sobre ella se reducen a un par de editoriales. Las noticias que aparecen en sus páginas, las transmitidas por los reporteros y las agencias, se centran mucho más en los incidentes fronterizos, y especialmente en los asaltos de Villa - muchos de ellos falsos-, a los que culparon, en gran parte, del deterioro de las relaciones bilaterales y, sobre todo, de la intervención militar norteamericana.

Por otra parte, sus sentimientos sobre los Estados Unidos tras la Guerra de Cuba llevan a los rotativos españoles - incluidos muchos de los que no comulgaban con el mandatario mexicano- a defender las posiciones de Carranza ante los norteamericanos, aunque sólo fuera porque, al menos aparentemente, supo hacer frente a las pretensiones de sus vecinos. De hecho, la intervención norteamericana fue, prácticamente, el único aspecto del proceso revolucionario que se vio reflejado en las páginas de los diarios sevillanos en forma de editoriales que, en general, coincidieron en la repulsa a los Estados Unidos y en su recuerdo - al que se recurre una y otra vez- de la guerra de Cuba.

A pesar de que algunos intelectuales españoles, como Vicente Blasco Ibáñez, no dejaran en buen lugar la tarea gubernativa del dirigente constitucionalista, los rotativos sevillanos, al margen de ideologías, siempre parecen observar con mayor benevolencia las posiciones de Venustiano Carranza que las de las autoridades estadounidenses. En éstas no ven sino un deseo de intervención en los asuntos internos de otro país, ya fuera, como señalaban algunos, con fines de expansión territorial, o para, como indicaban otros, defender sus negocios y, en definitiva, para lograr el dominio económico de la república.

El nacionalismo de Venustiano Carranza era suficiente para que la prensa española, incluida la conservadora, estuviera de su lado cuando el enemigo no era un líder interno más o menos cercano a la ideología de uno u otro periódico, sino un país que, poco antes, había despojado a España de uno de sus más preciados territorios, la isla de Cuba. Este hecho, que desde la península se tardaría en perdonar a la nueva potencia, se dejaría sentir con fuerza en las publicaciones de este lado del Atlántico a la hora de valorar el papel de ésta no sólo frente a Carranza, sino a lo largo de toda la Revolución mexicana, situándolo, incluso, en el origen del proceso. En este sentido es significativo un editorial publicado por El Liberal de Sevilla ya en 1914, en el que se afirmaba que "tal vez en el momento actual Méjico 
vive como vive y sufre como sufre, porque hay quien tiene especial empeño en que así suceda y en fomentar el mal hasta hacerlo endémico"; y aunque acusaba de ello "a las grandes potencias", en general, no parece haber duda de a qué gran potencia correspondía esa responsabilidad, ${ }^{85}$ que otros diarios, menos cautos, señalaban directamente, acusando a sus autoridades de "multiplicar el desorden" y abrir "las fronteras a la insurrección", para hacer caer a un mandatario que había dejado de ser lo suficientemente complaciente con sus intereses. ${ }^{86}$

Recibido el 16 de enero de 2008 Aceptado el 14 de abril de 2008

85 El Liberal de Sevilla, martes 14 de abril de 1914.

86 "Nuestra política en América", La Unión Iberoamericana, Madrid, julio de 1916, pág. 27. Cit. por Delgado Larios: La Revolución Mexicana..., pág. 284. 